Document downloaded from:

http://hdl.handle.net/10251/95446

This paper must be cited as:

Climente Alarcon, V.; J. Antonino-Daviu; Strangas, EG.; Riera-Guasp, M. (2015). Rotor-Bar Breakage Mechanism and Prognosis in an Induction Motor. IEEE Transactions on Industrial Electronics. 62(3):1814-1825. doi:10.1109/TIE.2014.2336604

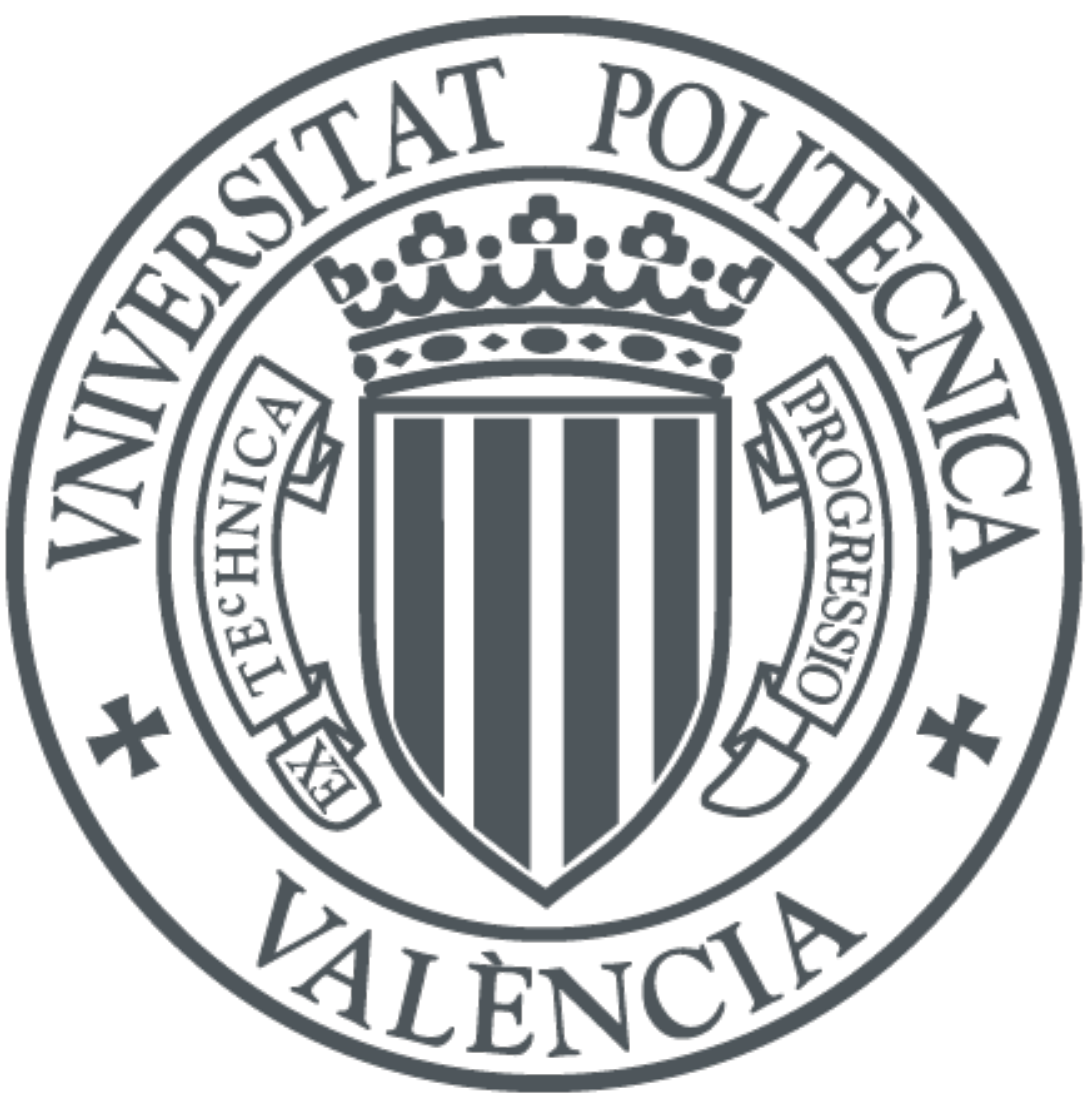

The final publication is available at

http://doi.org/10.1109/TIE.2014.2336604

Copyright Institute of Electrical and Electronics Engineers

Additional Information 


\title{
Rotor Bar Breakage Mechanism and Prognosis in an Induction Motor
}

\author{
Vicente Climente-Alarcon, Member, IEEE, Jose Alfonso Antonino-Daviu, Senior Member, IEEE, \\ Elias Strangas, Member, IEEE and Martin Riera-Guasp, Senior Member, IEEE
}

\begin{abstract}
This paper proposes a Condition-Based Maintenance and Prognostics and Health Management (CBM/PHM) methodology for a rotor bar in an induction motor, based on the results of a fatigue test intended to reproduce in the most natural way a bar breakage in order to carry out a comparison between transient and stationary diagnosis methods for incipient fault detection. Newly developed techniques in stator current transient analysis have allowed tracking the developing fault during the last part of the test, identifying the failure mechanism and establishing a physical model of the process. This non-linear failure model is applied by a Particle Filtering algorithm to diagnose the defect at an early stage and predict the Remaining Useful Life (RUL) of the bar. An initial generalization of the results to conditions differing from the ones under which the fatigue test was developed is studied.
\end{abstract}

Index Terms - Induction motors, rotors, fault diagnosis, failure analysis, fatigue, frequency-domain analysis, spectrogram, particle filters, prognostics and health management, remaining life assessment

\section{NOMENCLATURE}

a Crack length.

$C$ Paris' equation constant.

$e \quad$ Normalized energy.

$f \quad$ Supply frequency.

$I_{l} \quad$ Amplitude of the main current component.

$I_{L S H}$ Amplitude of the current's low sideband harmonic.

$I_{U S H}$ Amplitude of the current's upper sideband harmonic.

$I_{0} \quad$ Amplitude of the DC component.

$I_{2 f s} \quad$ Amplitude of the harmonic component at $2 f s \mathrm{~Hz}$.

$I_{4 f_{s}} \quad$ Amplitude of the harmonic component at $4 f_{s} \mathrm{~Hz}$.

$i \quad$ Current waveform.

$K_{l c}$ Low cycle fatigue's equation constant.

$K_{p} \quad$ Global Paris' equation constant.

$k \quad$ Particle number.

$m$ Paris' equation exponent.

$n \quad$ Predicted cycle number $(n=1,2 \ldots N)$

$N \quad$ Predicted failure cycle

$n_{d} \quad$ Process noise for the state variable

The authors are with the Department of Electrical Engineering and Automation, Aalto University, P.O. Box 13000, Aalto, 00076 FINLAND, email: viclial@ieee.org; Instituto de Ingeniería Energética, Universitat Politècnica de València, Camino de Vera s/n, 46022, Valencia, SPAIN, (phone: 0034-963877592, fax: 0034-963877599), e-mails: joanda@die.upv.es, mriera@die.upv.es; and Engineering College, Michigan State University, MI, USA, email: strangas@egr.msu.edu. $n_{l c}$ Process noise for the asymmetry indicator, low cycle fatigue

$n_{p} \quad$ Process noise for the asymmetry indicator, crack propagation

$s \quad$ slip

$t \quad$ Cycle number.

$t_{c} \quad$ Time interval for integration.

$w_{t}(k) \quad k$-th particle weight at cycle $t$.

$x_{t}^{*} \quad$ Predicted State of the system at startup $t$.

$\gamma_{\mathrm{F} 1}$ FFT's rotor asymmetry indicator (LSH).

$\gamma_{\mathrm{F} 2}$ FFT's rotor asymmetry indicator (LSH).

$\gamma_{\text {Hilbert }}$ Hilbert's rotor asymmetry indicator.

$\gamma_{\chi} \quad$ Wavelet's rotor asymmetry indicator of band $\chi$

$\gamma_{\mathrm{W}} \quad$ Wigner-Ville's rotor asymmetry indicator.

$\gamma_{\mathrm{W}}{ }^{*} \quad$ Predicted Wigner-Ville's rotor asymmetry indicator.

$\Delta K$ Stress intensity factor.

\section{INTRODUCTION}

$\mathrm{T}$ he new maintenance paradigm for critical equipment advocates for the determination of its current and probable future state of health with the aim of maximizing the asset's operational availability by optimally scheduled repairing activities. In order to achieve this objective, a complete Condition-Based Maintenance and Prognostics and Health Management (CBM/PHM) system must developed, requiring a better comprehension of the physics behind the failure and their evolution. Incipient fault detection and failure models are critical stages in this methodology since, for the first case, prognostics rely on early detection to carry out a timely and trustworthy prediction, therefore the fault's detection threshold should be reduced as far as it is practical; and secondly, the development of physics-based modeling of components allows a better understanding of the influence of external factors, the failure mechanisms and its propagation times [1].

In addition, the non-linear nature of such physical models, and in general, the inherent complexity of the tasks involved, recommends the use of newly developed fault detection and prognosis algorithms, over existing ones such as the Kalman filter [2]. Particle Filtering has been developed as a powerful method with low computational cost [3], combining a model and data driven approaches [4-6], where model deviations are corrected by new measurements using Bayesian theory, having already been applied to predict the Remaining Useful Life (RUL) of equipment $[1,6]$. 
The aim of this paper consist of, following the framework outlined in [1], introducing a full CBM/PHM procedure for diagnosing and estimating the RUL of a rotor bar in an induction motor, based on the results of a fatigue test intended to develop in the most natural way a bar breakage. The architecture proposed here (Fig. 1) could be extended to the failure of more than one bar or other elements in the secondary circuit of an induction motor to predict the RUL of the whole machine.

With that objective, this work develops a natural bar breakage, validates a method for incipient fault detection of rotor asymmetries, identifies low cycle thermal fatigue as the bar's failure mechanism, links stator current derived indicators with crack progression in the cage, fits a crack progression expression to one of such indicators, uses that expression in a Condition-Based Maintenance and Prognosis and Health Management methodology based on Particle Filtering and finally studies an initial generalization of the results for startups whose severity differs to the one carried out during the fatigue test.

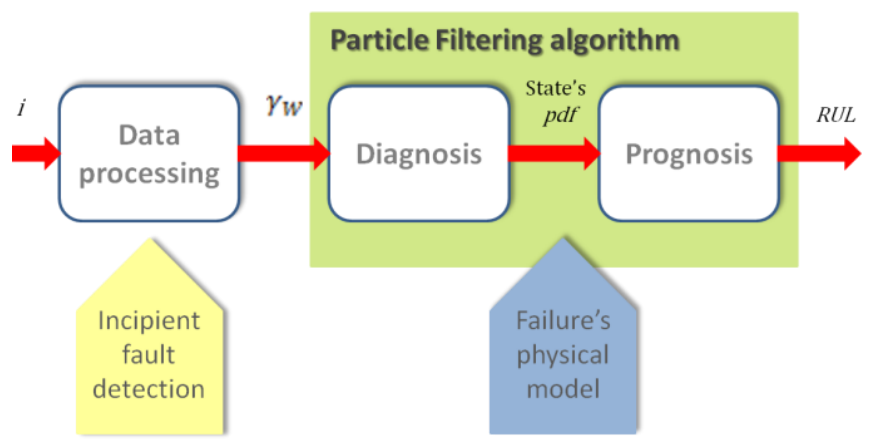

Fig. 1. Proposed CBM/PHM procedure. The results of the fatigue test have allowed establishing an incipient fault detection procedure and a physical model of the breakage needed for a correct prognosis of the fault

Rotor asymmetries, and among them, bar and end ring breakages, are responsible for up to $10 \%$ of the failures of induction motors. Generally, this fault affects large units featuring a fabricated cage [7] and started at grid's frequency under high inertia, with high downtime and repair costs and often difficult replacement.

The diagnosis of rotor asymmetries has been a subject of detailed study in the last years, applying, in order to detect it, a wide battery of signal processing methods to magnitudes such as vibrations [8], voltages [9], flux and currents [7]; prevailing the techniques belonging to this later group due to their effectiveness and easy application, especially the ones that use the decomposition in frequency of the current waveform, known as Motor Current Signature Analysis (MCSA), which are of widespread use in the industry.

Recently, research has been focused on special aspects of rotor asymmetries, such as the load's influence in the traditional MCSA-based diagnosis [10], the effect of rotor ducts [11], partial breakage detection [12, 13, 14] and diagnosis in transient regime [15], under which the FFT analysis proves useless. In fact, one of the seminal works on transient current analysis, by Elder et Al., pointed out towards combining both of these approaches [16] in the study of direct startup transient since under such condition the machine is under severe electrical and mechanical stress, and thus faults as broken rotor bars could be detected at an earlier stage. The fatigue test whose results are presented in this paper was conceived to prove this hypothesis.

Destructive studies of rotor bars have already being carried out by Cabanas et Al. in [17], in a combined FEM and experimental approach that computed forces acting on this component under its most stressful working conditions, that is, during a direct on-line startup, and later cyclically replicated them on test especimens. The conclusions of this work showed that the mechanical loads alone on the bars of a constructed cage are not responsible for their failure, even if manufacturing defects exist, thus recognizing in this study the importance of thermal aspects $[18,19]$ in the development of the fault.

Furthermore, the authors in [17] compare their results with high cycle fatigue models, failure theory that is focused in evolutions ranging between $10^{4}$ to $10^{6}$ cycles, whilst large motor manufacturers design the rotor cages for just several thousand startups [20]. Therefore, just drawing the right conclusions from already published data, it can be hypothesized that a bar breakage should be modeled using low-cycle thermal fatigue expressions [21] (conceived for $10^{2}$ to $10^{3}$ cycles). In this case, crack propagation models, just spanning from $10^{2}$ to $10^{3}$ cycles and therefore worthless under high fatigue, may explain a significant part of the damage's evolution (Fig. 1 of [17]).

Thus, the main contributions of this work are:

- Providing for the first time a procedure to accurately monitor the evolution of a rotor bar breakage in large induction motors by comparing different techniques during a fatigue test. Previous studies have only been focused on diagnosing partial breakages [12, 13, 14].

- Applying for the first time crack propagation expressions in order to properly model that observed evolution, as opposed to the high cycle fatigue ones used in $[17,18$, 19].

- Confirming the effect of constructive rotor asymmetries in the incipient detection of this fault, not detected in previous partial breakage studies [12, 13, 14].

- Yielding a complete CBM/PHM system able to monitor and predict the state of one rotor bar.

- Studying a first generalization of the results to different severity startups.

For these purposes, this work is structured as follows: in Section II the experimental procedure used for development of the fault -already introduced in [22] - is completed, Section III validates a method to track the evolution of the fault and expands the results presented in [23], followed in Section IV by a discussion of them, linking transient current indicators to the evolution of the breakage. This enables in Section $\mathrm{V}$ to propose a physical model of the failure and introducing a novel state estimation and prognosis module using the Particle Filtering approach based on this fault model, and finally, 
Section VI yields the conclusions.

\section{EXPERIMENTAL PROCEDURE}

The methodology undertaken to cause and monitor the bar breakage, introduced in [22], is reproduced in this section highlighting the modifications added during the last part of the experiment.

\section{A. Test stand}

A one pole pair induction motor whose characteristics are exposed in the Appendix was coupled to a DC Machine, having an inertia of $0.11 \mathrm{~kg} \cdot \mathrm{m}^{2}$, and subjected to an operational cycle that included a heavy startup and a stationary period (Fig. 2-3). Currents in two phases (A and C), vibrations at the middle of the stator, rotational speed and stator and external temperatures were recorded for each cycle by a Yokogawa DL-750 digital oscilloscope (Fig. 4).

A current was captured by means of a $60 \mathrm{mV}, 6 \mathrm{~A}$ shunt, mounted on the secondary winding of a 15/5, 0.5 class current transformer whilst, in the last epoch of the fatigue test, a 10 mV/A current clamp was used to acquire the other. An industrial accelerometer with a resolution of $10 \mathrm{mg} / \mathrm{V}$ intended to capture the effect of mechanical vibrations originated by electromagnetic causes.

The rotating speed was measured through an encoder. In addition, two thermocouples provided the temperature on the stator and a reference from the surroundings.

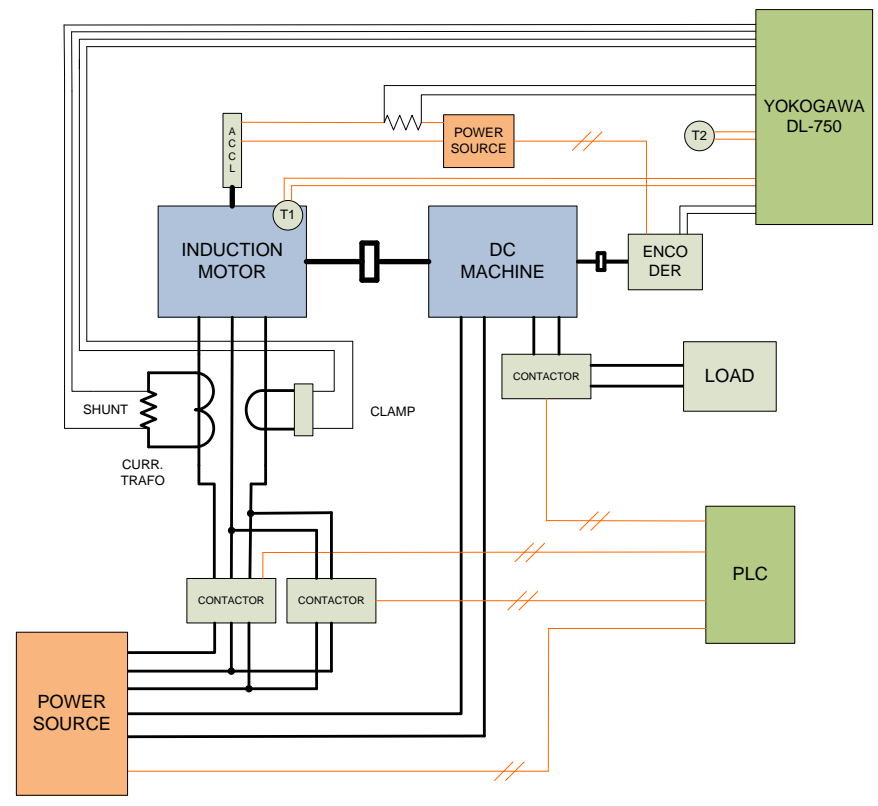

Fig. 2. Diagram of connections between elements of the test stand.

The first thermocouple permitted adjusting the length of the inactive interval between cycles in order to avoid damage on the stator windings, whilst a comparison with the second enhanced the identification of cold startups. A sampling rate of $5 \mathrm{kHz}$ and a resolution of 16 bits were used for recording the signals during the last epoch of the fatigue test. The up to $500 \mathrm{MB}$ of data recorded each day of operation were transferred via intranet to a PC and automatically analyzed and compressed.

Fig. 4 shows the recorded waveforms of test number 80,000 . The startup transient lasted seven seconds, being followed by stationary operation until around the $20^{\text {th }}$ second after connection. A plug stopping, lasting six seconds, was added after cycle 60,000 in order to increase the stress in the rotor cage. Further details of the experimental setup and the results after the first 40,000 cycles were presented in [22].

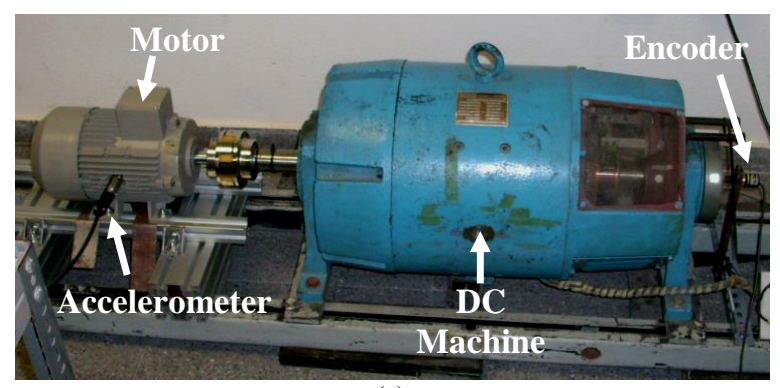

(a)

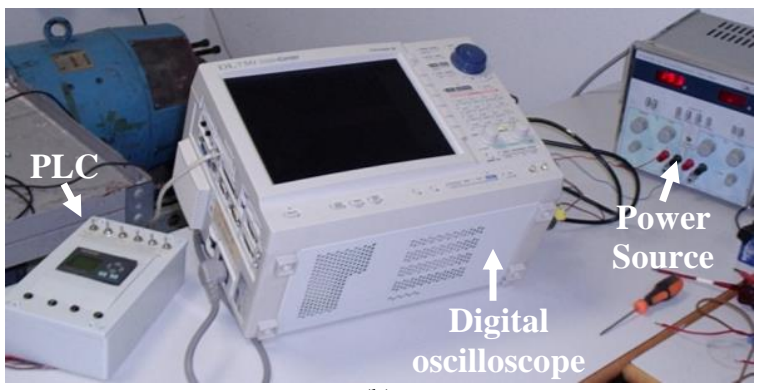

(b)

Fig. 3. Experimental test stand, (a) motor-load unit, (b) control and monitoring equipment.
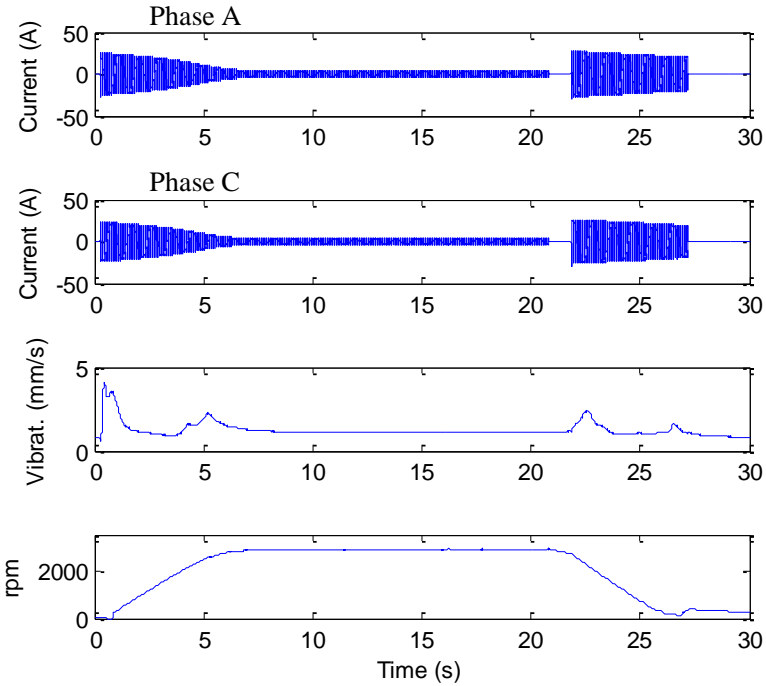

Fig. 4. Signals recorded for test number 80,000.Currents in two phases, vibration and speed (plus stator and external temperature not shown).

\section{B. Stationary indicators computed}

As it was introduced in [22], several fault indicators adapted to the detection of a rotor asymmetry and based in the study of just one stator current were computed with the aim of 
determining and comparing their fault detection thresholds. Three indicators based on the study of the stator current during the last 10 seconds of stationary operation of each test were calculated.

1) The first one compares the amplitude of the low sideband harmonic, LSH, to the amplitude of the fundamental component from the current spectrum (1). In order to increase its accuracy, a Blackman window was used to avoid leakage effects and the Teager-Kaiser algorithm, having a minimal computational cost, was utilized to enhance the automatic peak detection [24] in an interval determined by the encoder reading.

$$
\gamma_{F 1}(d B)=20 \cdot \log \left(\frac{I_{1}}{I_{L S H}}\right)
$$

2) The second indicator modifies (1) also taking into account the amplitude of the upper sideband harmonic (2), as it is recommended in the bibliography [7].

$$
\gamma_{F 2}(d B)=20 \cdot \log \left(\frac{I_{1}}{I_{L S H}+I_{U S H}}\right)
$$

3) Finally, also for the stationary operation, a third indicator was computed. It is based on studying the spectrum of the envelope obtained from the application of the Hilbert transform to the stator current [15]. This enables the suppression of the main current component and thus improved sideband detection. Their energy is compared to the amplitude of the DC component (3).

$$
\gamma_{\text {Hilbert }}(d B)=20 \cdot \log \left(\frac{I_{0}}{I_{2 f s}+I_{4 f s}}\right)
$$

\section{Transient indicators computed}

For transient operation, Wavelet-based indicators (4) and the integration of the energy of the LSH using the WignerVille distribution (5), both having low computational requirements and not needing a speed profile, were computed:

4) The Wavelet indicator [22], takes into account the energy present in a whole band whose limits are determined by the decomposition, by comparing the energy present in one detail or approximation $\chi$ with the energy in the original current waveform $i$, between the limits $N s$ and $N b$, to avoid edge effects (4).

$$
\gamma_{\chi}(d B)=10 \cdot \log \left[\frac{\sum_{j=N b}^{N s} i_{j}^{2}}{\sum_{j=N b}^{N s}[\chi(j)]^{2}}\right]
$$

5) The Wigner-Ville indicator, proposed in [25], was developed during the fatigue test with the objective of reducing the influence of noise and other minor amplitude components evolving during the startup that caused a high value of the standard deviation (Table II) for the most critical Wavelet indicators (4), which could hinder adequate incipient fault detection. In this case, the Wigner-Ville transform is utilized to obtain a time-frequency distribution of the energy of the current in a range whose limits can be set freely by use of band pass and notch filters. This time-frequency boxes are selected to isolate prevailing fault harmonics, whose evolution can be tracked by means of the computation of the instantaneous frequency and their energy $e_{i f, b w}$ integrated on that track, therefore avoiding contributions of other harmonics or interferences (5):

$$
\gamma_{W}(d B)=10 \cdot \log \left[\frac{2 \sum_{t_{c}} i_{j}^{2}}{e_{i f, b w}}\right]
$$

The selected time-frequency box studied here corresponds to the last part of the evolution of the LSH harmonic, between 0 and $45 \mathrm{~Hz}$ during the second part of the startup, in which the effect of cage's resistance is predominant in the rotor currents. The indicator (5) has been normalized, yielding values comparable to the application of (1) and (2) to the analysis of a rotor asymmetry in stationary operation.

\section{RESULTS OF THE FATIGUE TEST}

The fatigue test comprises 82,265 cycles. As no evolution was seen in the indicators, the rotor was progressively weakened. This procedure was carried out removing material from the end rings, in their junction with the rotor bars. In [22] the results of a symmetric lathing process, carried out after test number 33,477, were presented. In spite of that, the prolongation of the test up to 79,007 cycles showed no trend in the bar breakage indicators (both for stationary and transient operation), and therefore it was decided to further debilitate one of the bars. No procedure was carried out to select a specific one.

\section{A. Modifications of the rotor}

In order to proceed with this weakening, two holes were drilled in the junction of a bar to the short circuit ring, inside the groove left by the lathing process. The diameter of the holes drilled, initially $3 \mathrm{~mm}$, was increased to $4 \mathrm{~mm}$ (bar section reduced to $14 \%$ ), and then to $4.5 \mathrm{~mm}$ one of them (bar section reduced to $7 \%$ ), until the bar breakage developed.

This machining modified the original structure of the casted squirrel cage, becoming it similar to a welded one, since the lathing process increased the cantilevered disposition of the end rings, and the holes near the bar produced a configuration alike to a bar protruding from the rotor iron to reach the ring.

\section{B. Indicators behavior}

Table I shows the average value of the stationary indicators (1), (2), (3) during the fatigue test. The first epoch corresponds to a healthy rotor. The second one spans the operation of the rotor cage after the lathing process, which removed $70 \%$ of the material in contact with the bars. Finally, the third epoch covers the final startups of the fatigue test, when one bar was weakened drilling two holes around its junction to the end ring. Each indicator is calculated for both phases $\mathrm{A}$ and $\mathrm{C}$. Table II introduces the results of the study of the LSH during the startup using the transient indicators (4), (5).

The difference of value before and after the bar breakage is noticeable for all the cases. It is remarkable that a clear increase in all indicators appears when the remaining section of the bar was reduced to $14 \%$ of the original one (see columns designed as "compensation" and (a1) in Fig. 5, 6, 7). 
TABLE I

EVOLUTION OF THE STATIONARY INDICATORS DURING THE FATIGUE TEST.

\begin{tabular}{|c|c|c|c|c|c|c|c|c|c|}
\hline \multirow{3}{*}{\multicolumn{2}{|c|}{$\begin{array}{l}\text { Indicator Phase } \\
\text { Cycles } \rightarrow\end{array}$}} & \multirow{2}{*}{\multicolumn{2}{|c|}{$\begin{array}{c}\text { First epoch } \\
1-33,477 \\
\end{array}$}} & \multirow{2}{*}{\multicolumn{2}{|c|}{$\begin{array}{c}\text { Second epoch } \\
33,478-79,007 \\
\end{array}$}} & \multicolumn{4}{|c|}{ Third epoch } \\
\hline & & & & & & \multicolumn{2}{|c|}{$\begin{array}{c}\text { Compensation } \\
\mathbf{8 0 , 4 0 5 - 8 0 , 8 5 7} \\
\end{array}$} & \multicolumn{2}{|c|}{$\begin{array}{l}\text { After Breakage } \\
81,216-81,653\end{array}$} \\
\hline & & $\bar{\gamma}$ & $\operatorname{std}(\gamma)$ & $\bar{\gamma}$ & $\operatorname{std}(\gamma)$ & $\bar{\gamma}$ & $\operatorname{std}(\gamma)$ & $\bar{\gamma}$ & $\operatorname{std}(\gamma)$ \\
\hline \multirow[b]{2}{*}{$\gamma_{\mathrm{F} 1(1)}$} & A & 42.8 & 0.8 & 40.9 & 1.3 & 49.3 & 0.5 & 39.8 & 0.5 \\
\hline & $\mathrm{C}$ & 42.5 & 0.6 & 40.8 & 0.9 & 46 & 0.5 & 40.1 & 0.5 \\
\hline \multirow[b]{2}{*}{$\gamma_{\mathrm{F} 2(2)}$} & A & 41.3 & 0.7 & 39.5 & 1.1 & 46.2 & 0.4 & 37.5 & 0.5 \\
\hline & $\mathrm{C}$ & 41 & 0.5 & 39.3 & 0.7 & 43.2 & 0.4 & 37.6 & 0.4 \\
\hline \multirow{2}{*}{$\gamma_{\text {Hilbert, (3) }}$} & A & 46.7 & 1.1 & 45.7 & 1.3 & 47.5 & 1.1 & 43.6 & 1.1 \\
\hline & $\mathrm{C}$ & 46.7 & 1.1 & 45.4 & 1.1 & 46.3 & 1 & 44.2 & 1 \\
\hline
\end{tabular}

TABLE II

EVOLUTION OF THE TRANSIENT INDICATORS DURING THE FATIGUE TEST.

\begin{tabular}{|c|c|c|c|c|c|c|c|c|c|}
\hline \multirow{2}{*}{\multicolumn{2}{|c|}{$\begin{array}{l}\text { Indicator Phase } \\
\text { Cycles } \rightarrow\end{array}$}} & \multirow{2}{*}{\multicolumn{2}{|c|}{$\begin{array}{c}\text { First epoch } \\
1-33,477\end{array}$}} & \multirow{2}{*}{\multicolumn{2}{|c|}{$\begin{array}{c}\text { Second epoch } \\
33,478-79,007\end{array}$}} & \multicolumn{4}{|c|}{ Third epoch } \\
\hline & & & & & & \multicolumn{2}{|c|}{$\begin{array}{l}\text { Compensation } \\
\mathbf{8 0 , 4 0 5}-\mathbf{8 0 , 8 5 7}\end{array}$} & \multicolumn{2}{|c|}{$\begin{array}{l}\text { After Breakage } \\
\mathbf{8 1 , 2 1 6 - 8 1 , 6 5 3}\end{array}$} \\
\hline & & $\bar{\gamma}$ & $\operatorname{std}(\gamma)$ & $\bar{\gamma}$ & $\operatorname{std}(\gamma)$ & $\bar{\gamma}$ & $\operatorname{std}(\gamma)$ & $\bar{\gamma}$ & $\operatorname{std}(\gamma)$ \\
\hline \multirow[b]{2}{*}{$\gamma_{\text {Apr6, (4) }}$} & A & 46.2 & 0.3 & 44 & 0.5 & 47.2 & 0.3 & 35.7 & 0.2 \\
\hline & $\mathrm{C}$ & 46.2 & 0.3 & 44 & 0.3 & 47.4 & 0.3 & 35.9 & 0.2 \\
\hline \multirow[b]{2}{*}{$\gamma_{\operatorname{Det} 7,(4)}$} & A & 46.5 & 0.3 & 44.5 & 0.5 & 47.7 & 0.3 & 36.8 & 0.3 \\
\hline & $\mathrm{C}$ & 46.5 & 0.3 & 44.5 & 0.3 & 47.7 & 0.3 & 37 & 0.3 \\
\hline \multirow[b]{2}{*}{$\gamma_{\mathrm{Apr} 7,(4)}$} & A & 58.1 & 1.9 & 53.9 & 1.4 & 57.2 & 1.3 & 42.2 & 0.8 \\
\hline & $\mathrm{C}$ & 58.3 & 2 & 53.9 & 1.1 & 58.8 & 1.1 & 42.8 & 0.9 \\
\hline \multirow[b]{2}{*}{$\gamma_{\text {Det8, (4) }}$} & A & 61.1 & 1 & 54.7 & 1.4 & 59.6 & 0.9 & 42.7 & 0.9 \\
\hline & $\mathrm{C}$ & 61.2 & 1 & 54.7 & 1.2 & 59.9 & 0.9 & 43.1 & 0.9 \\
\hline \multirow{2}{*}{$\gamma_{\mathrm{W},(5)}$} & A & 50 & 0.8 & 43.5 & 0.3 & 55.7 & 0.9 & 33.5 & 0.1 \\
\hline & $\mathrm{C}$ & 50.1 & 0.7 & 43.5 & 0.3 & 56.2 & 1 & 33.9 & 0.1 \\
\hline
\end{tabular}

This behavior is due to the fact that the LSH produced by the forced incipient fault is combined with the small LSH due to the inherent asymmetry of the cage, performing as a double incipient fault; but as it is shown in [26] and depending on the relative position of both fault components (incipient and inherent LSH in this case), the resultant LSH can grow or can be compensated reducing its value, as it happens in the performed test, yielding higher indicators.

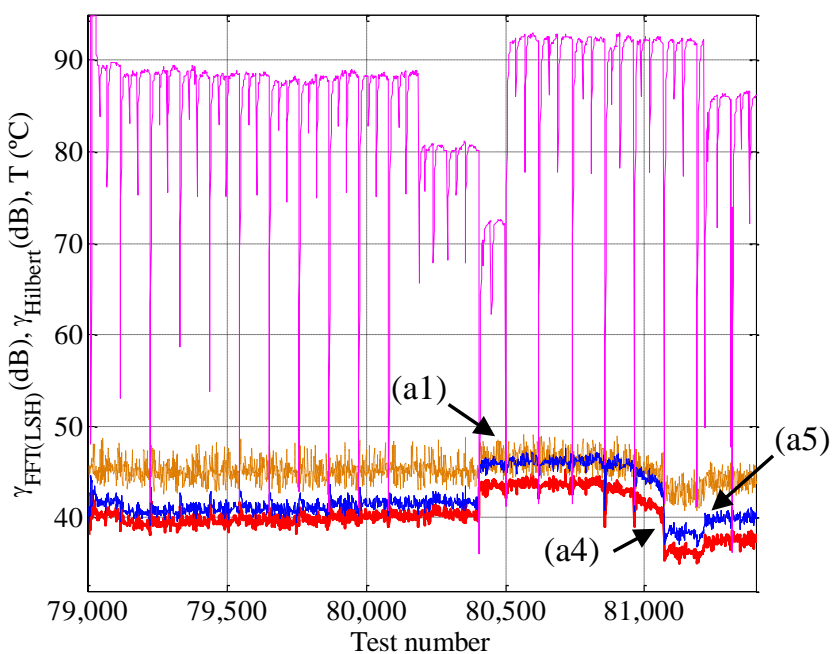

Fig. 5. Stationary rotor asymmetry indicators and stator temperature during the last stage of the fatigue test, phase C. Red, FFT indicator $\gamma_{\mathrm{F} 2}(2)$; Blue, FFT indicator $\gamma_{\mathrm{Fl}}(1)$; Brown, Hilbert indicator $\gamma_{\text {Hilbert }}(3)$. Rose, stator temperature.

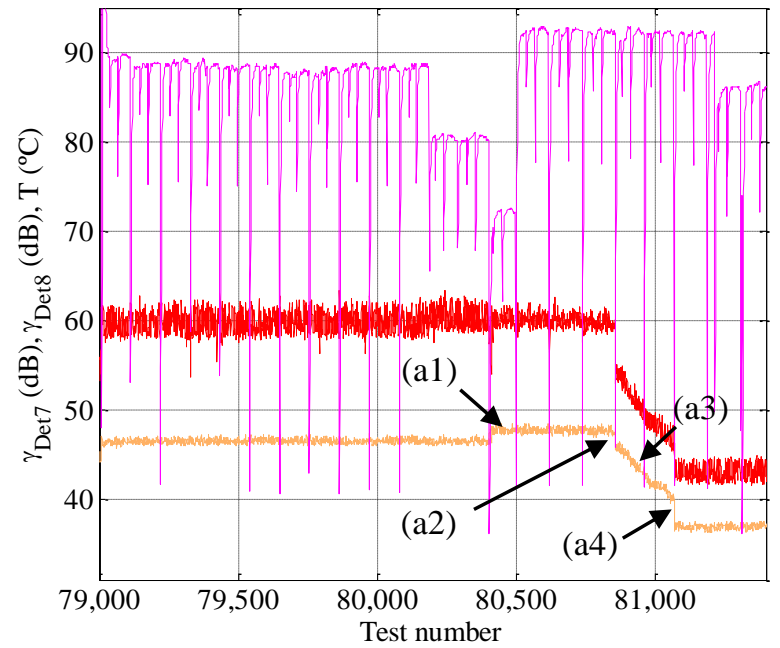

Fig. 6. Transient rotor asymmetry Wavelet indicators and stator temperature during the last stage of the fatigue test, phase C. Orange, Wavelet Detail 7 indicator $\gamma_{\text {Det7, }}$ (4); red, Wavelet Detail 8 indicator $\gamma_{\text {Det8, }}$ (4). Rose, stator

This result is interesting, since it suggests that an incipient fault, in its initial stage, should be detected through a slight variation of the fault indicators (increase or decrease) and not necessarily through a decrease of these parameters.

Moreover, if Fig. 5 showing the stationary indicators is compared to Fig. 6 and 7, which present the transient ones, a much clearer evolution is detected in the last ones once the section of the bar was reduced to $7 \%$ of its original value. First 
of all, the increase of the diameter of one drill from $4 \mathrm{~mm}$ to $4.5 \mathrm{~mm}$ is clearly presented by a sudden reduction of the indicators (a2). Further, an unambiguous trend in the transient indicators is observed, as the bar weakens (a3). The full breakage occurred after the second startup following a long stop in which the machine reached room temperature (a4).

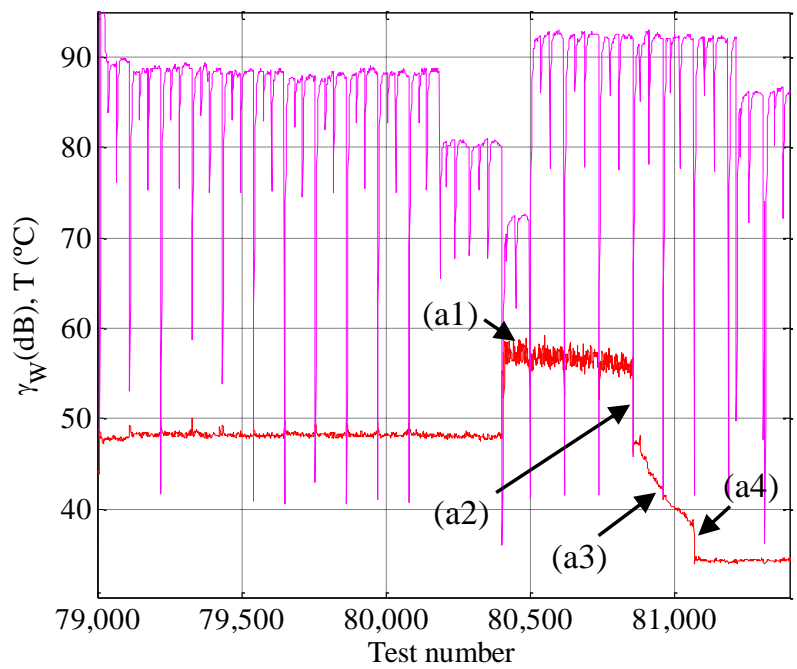

Fig. 7. Transient rotor asymmetry Wigner-Ville-based indicator $\gamma_{W}(5)$ (red) for phase $\mathrm{C}$, and stator temperature during the last stage of the fatigue test (rose).

Thus, the conclusions of the fatigue test support the hypothesis presented in [16]: the study of the direct startup of an induction motor yields a more accurate view of its rotor asymmetry [23].

\section{Bar inspection}

Once the rotor was inspected after the indicators stabilized, surprisingly no apparent damage was seen. The bridge between the holes was still in its position. However, a detailed comparison between the pictures taken before and after the breakage (Fig. 8 and Fig. 9) showed some damage, material lost at the junction between the ring and the bar and a crack down the $4 \mathrm{~mm}$ drill.

Fig. 10 presents a combination of pictures showing this crack (b2) using materials lenses, whose limited depth of field only allow to correctly focusing a few millimeters of the hole at a time. The crack clearly continues deep inside it. The cavities left by the material lost in the upper side of the bar are well seen (b1). Furthermore, an aluminum drop hanging from the hollow where it was formed is also identified (b3).

\section{DISCUSSION OF THE RESUlTS}

The bar breakage process achieved during the fatigue test showed a more complicated pattern than initially thought.

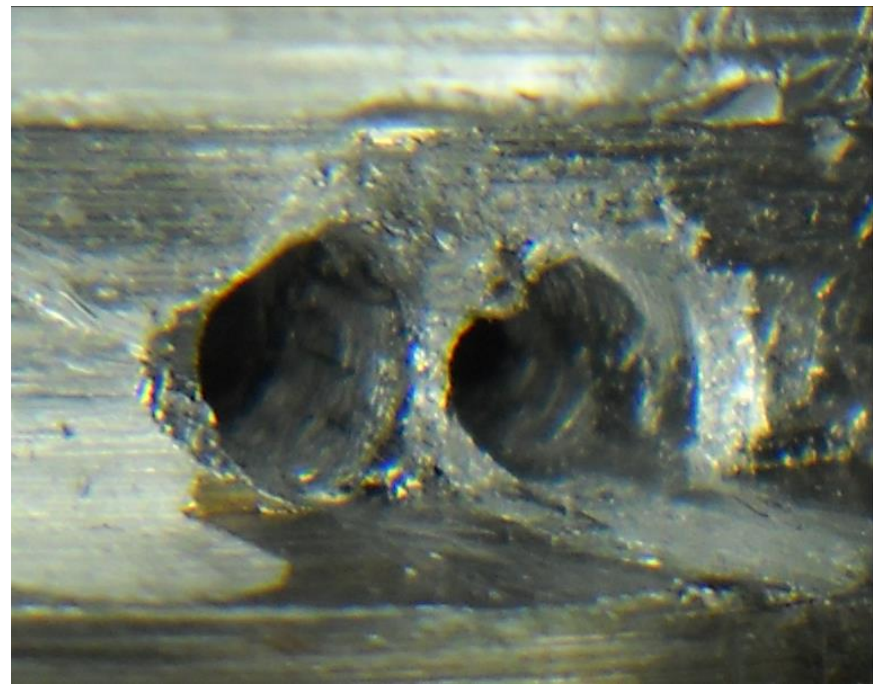

Fig. 8. Bridge between the bar and the end ring before the breakage.

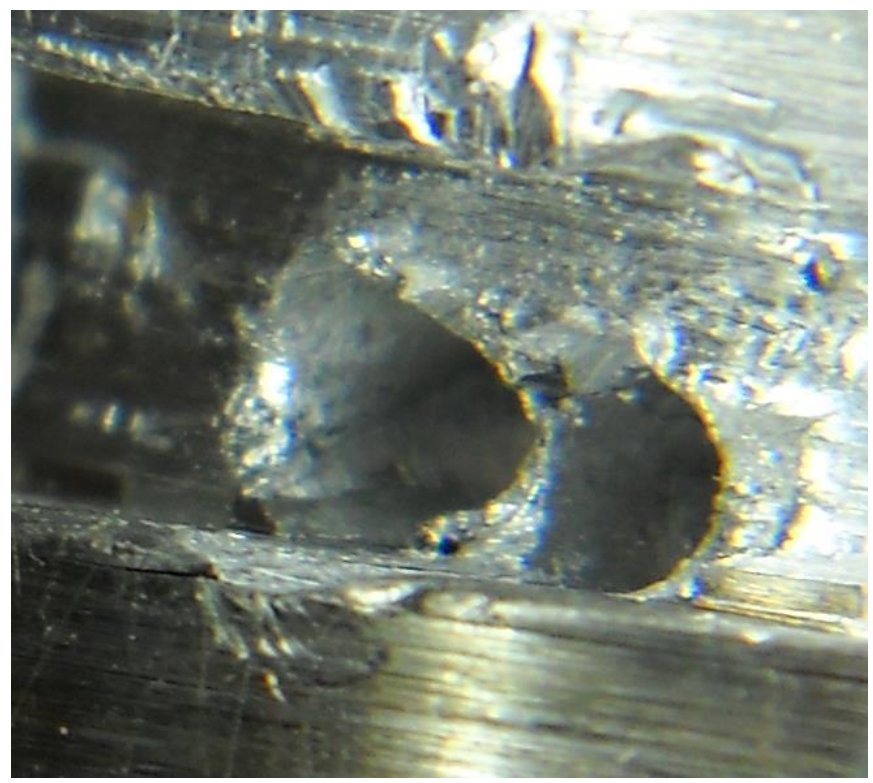

Fig. 9. Bridge between the bar and the ring after the breakage.

\section{A. Compensation of a previous rotor asymmetry}

It is observed that the evolution of the rotor asymmetry indicators, contrary to what it is expected, increases its value as a bar is weakened (Fig. 5, 6, 7 and Tables I and II). This effect is attributed to the compensation of a slight previous asymmetry due to a constructive defect in a bar at half the pole pitch of the one that was weakened, as it is indicated in [26]. The study of the rotor asymmetry high order harmonics during the breakage confirms this hypothesis [27], which is also supported by the results of subjecting a faulty motor of the same characteristics, used in [25], to the same cycling. As shown in Table III, the initial inherent rotor asymmetry of this machine was lower and all the indicators suffer a wider variation. 


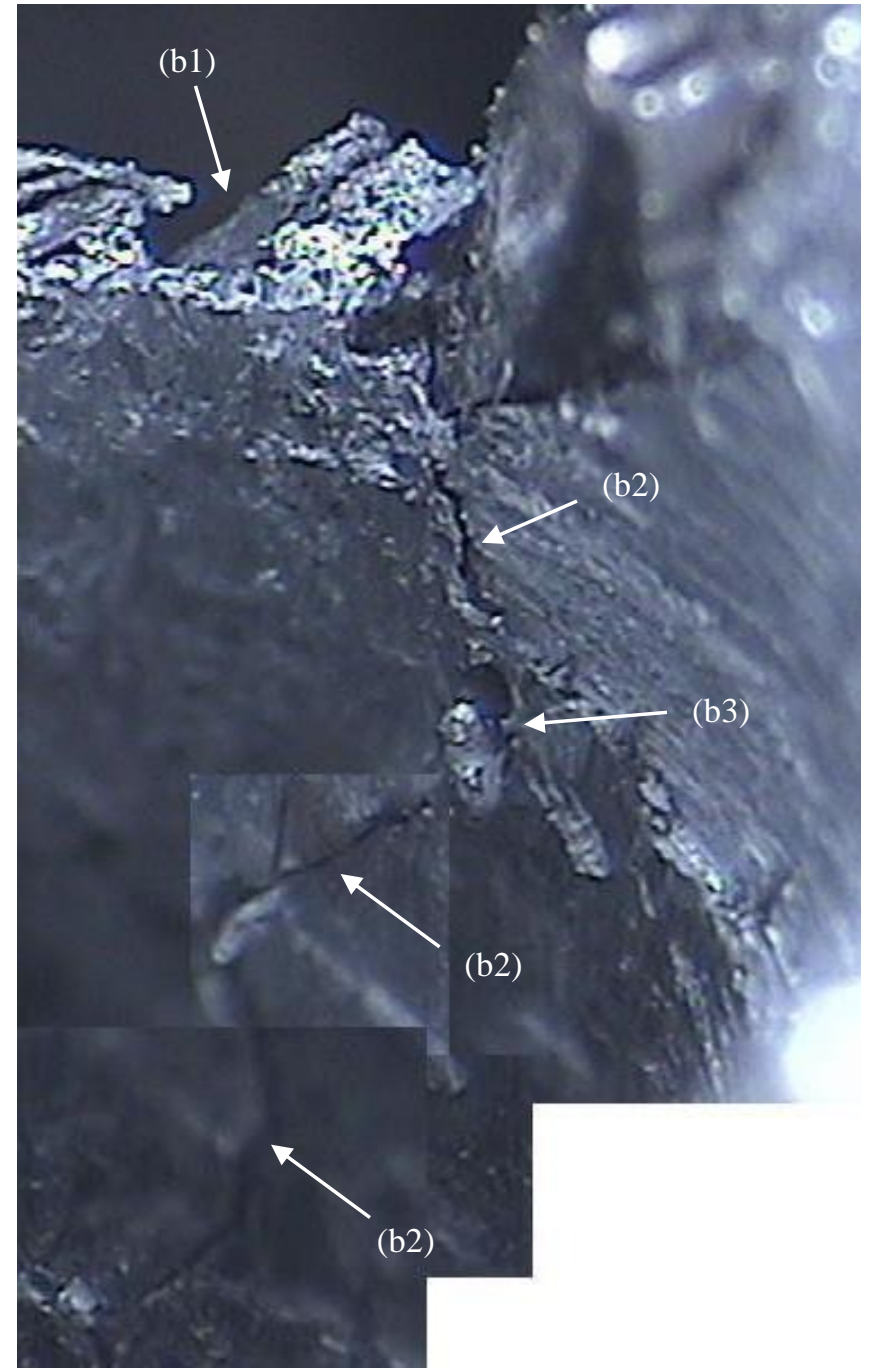

Fig. 10. $4 \mathrm{~mm}$ drill after the breakage. A crack and a molten aluminum drop are clearly visible.

TABLE III ROTOR ASYMMETRY

INDICATORS FOR THE SECOND MOTOR.

\begin{tabular}{ccccc}
\hline \hline \multirow{2}{*}{ Indicator } & \multirow{2}{*}{ Phase } & \multirow{2}{*}{ Healthy } & \multicolumn{2}{c}{ Faulty } \\
\cline { 3 - 5 } & & $\gamma$ & $\bar{\gamma}$ & std $(\gamma)$ \\
\hline \multirow{2}{*}{$\gamma_{\mathrm{F} 1(1)}$} & $\mathrm{A}$ & 45.4 & 32.6 & 0.4 \\
& $\mathrm{C}$ & 41 & 32.4 & 0.4 \\
$\gamma_{\mathrm{F} 2(2)}$ & $\mathrm{A}$ & 43.5 & 31.8 & 0.4 \\
& $\mathrm{C}$ & 41.9 & 31.8 & 0.4 \\
$\gamma_{\text {Hilbert, (3) }}$ & $\mathrm{A}$ & 49 & 39.8 & 1.1 \\
& $\mathrm{C}$ & 47.2 & 39.7 & 1.1 \\
$\gamma_{\text {Apr6, (4) }}$ & $\mathrm{A}$ & 47.2 & 35.4 & 0.1 \\
& $\mathrm{C}$ & 47.3 & 35.8 & 0.1 \\
$\gamma_{\text {Det7, (4) }}$ & $\mathrm{A}$ & 47.5 & 36.2 & 0.2 \\
& $\mathrm{C}$ & 47.6 & 36.4 & 0.2 \\
$\gamma_{\mathrm{Apr} 7,(4)}$ & $\mathrm{A}$ & 59.6 & 43.3 & 0.8 \\
& $\mathrm{C}$ & 60.6 & 44.3 & 1 \\
$\gamma_{\text {Det8, (4) }}$ & $\mathrm{A}$ & 66.9 & 43.8 & 0.9 \\
& $\mathrm{C}$ & 67 & 44.6 & 1 \\
$\gamma_{\mathrm{W},(5)}$ & $\mathrm{A}$ & 54.5 & 33.9 & 0.1 \\
\hline \hline
\end{tabular}

\section{B. Influence of other factors on the traditional indicators}

The disassembling and reassembling of the motor in order to check the breakage, has a clear effect in the stationary indicators that increase their value (Fig. 5, a5), whilst the transient based ones remain unaffected (Fig. 6, 7). The average variation is $1.7 \mathrm{~dB}$ for (1), $1.35 \mathrm{~dB}$ for (2) and $0.8 \mathrm{~dB}$ for (3). This effect can be a product of a modification of the static eccentricity as stated in [10]. Therefore, in experiments trying to detect a partial breakage using stationary indicators, some slight variations of the indicators may be product of unintentional modifications in the position of the rotor within the stator bore when it was extracted in order to artificially cause the damage, and not an effect of the incipient fault.

\section{Trends observed during the bar breakage}

As the section of the bar is reduced to an estimated $14 \%$ of its original area (test number 80,405) and the compensation is achieved, a slight trend in the rotor asymmetry wavelet indicators is appreciated (Fig. 6). In the latter developed method based in the Wigner-Ville distribution, this evolution is wider (Fig. 7 and 11, (a1) and (c1) respectively).

For phase A, in 452 tests, the indicator is reduced by $1.7 \mathrm{~dB}$ (Fig. 11). In addition, the slope increases as this series of tests progresses.

Once the remaining section is reduced to the $7 \%$ of the original (test number 80,857), by increasing the diameter of a hole in $0.5 \mathrm{~mm}$ (Fig. 6, 7 (a2), Fig. 11 (c2)), the evolution is much faster (a3, c3) until the bar abruptly breaks (a4, c4) after 214 additional tests, that is, between cycles 81,070 and 81,071 . There is no further evolution in the indicator (c5).

This behavior well fits into the evolution of a crack: a growing period (c1, c3) and once the section has been reduced enough, a sudden breakage (c4) occurs.

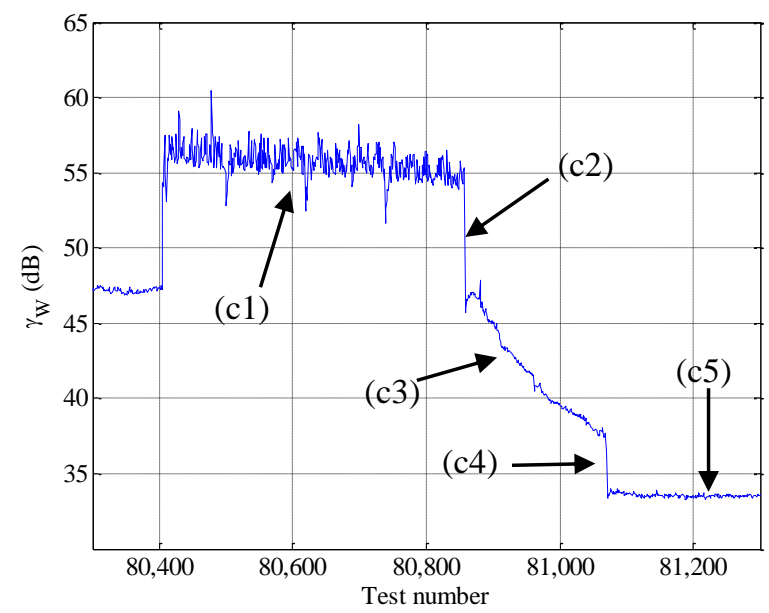

Fig. 11. Wigner-Ville indicator $\gamma_{\mathrm{W}}$ (5) for phase A assessing the energy of the LSH in the startup during the bar weakening and breakage.

It must be noted that although there are signs of creep at the upper part of the remaining bar, with material lost, and in the hole itself (the aluminum drop), similar as detected on large casted aluminum cage's faults [18], the breakage mechanism according to Fig. 11, corresponds to the behavior of a crack propagation, as observed during the visual analysis of broken 
bars in fabricated cages [17].

Qualitatively, from the relatively rapid development of the failure, below ten thousand cycles, it is inferred that the breakage can be modeled as low cycle fatigue [21]. Furthermore, both the behavior of the transient indicators and the effects that appeared on the surface of the aluminum (Fig. $10, \mathrm{~b} 2$ ), point out to the predominance of stress-strain, caused by thermal expansion and contraction, over creep. Therefore and contrary to what has been tried in previous studies [1719], the equations modeling low cycle (thermal) fatigue and crack propagation could be applied to estimate the remaining life of a bar, once an evolution in the rotor asymmetry indicators based on the study of the transient current has been detected

\section{Conclusions of the fatigue test}

The objective of causing a natural bar breakage on a small induction motor featuring a casted aluminum cage proved difficult to achieve through heavy transients without artificially decreasing the section of a bar. No natural evolution could be appreciated in the rotor asymmetry indicators based on the analysis of a stator current until the remaining section was reduced to $14 \%$ of the original. Even in this case, the existence of small constructive defects in the secondary circuit of the motor may cause indicators based on the study of low frequency harmonics to initially react opposite to what is expected.

The results of the fatigue test validated the initial hypothesis that transient analysis of stator startup currents can earlier detect a bar fault and, in addition, yielded a method to accurately track the breakage process. This and the inspection of the bar after the failure have allowed characterizing this process as low cycle thermal fatigue, with a significant final stage of crack propagation. The fact that the growing of this crack is clearly depicted by the transient indicators links the failure mechanism to a magnitude that can easily be measured externally to the machine, thus permitting in the next section to propose a model easy to implement in real applications, useful not only in the diagnosis but, especially in the prognosis of the fault.

\section{FAult Detection ANd Prognosis Module}

In this section an implementation of a state estimation and prognosis module for a rotor bar is proposed. This algorithm takes advantage of a physical model of the failure obtained from the data yielded by the fatigue test.

\section{A. Crack propagation model}

The rapid evolution (c3) observed in Fig. 11 once the section of the bar had been decreased to a $7 \%$ of its original value and its sudden collapse (c4) invites the application of fracture theory to model this behavior.

The Paris equation [5] relates the growth rate of a crack having a length $a$ to the stress intensity factor $\Delta K$, which is linked to the range of cyclic stress, by means of two constants of the material, $C$ and $m$ :

$$
\frac{d a}{d n}=C \cdot \Delta K^{m}
$$

For aluminum $\left(m=3, C=10^{-12}\right)$ the integration of this equation yields:

$$
\left|a_{i}^{-1 / 2}-a_{0}^{-1 / 2}\right|=-\frac{1}{6} \cdot C \cdot \Delta K^{3} \cdot N_{f}
$$

being $N_{f}$ the number of load cycles.

Taking into account the evolution of the Wigner-Ville parameter as the development of the crack and fitting the expression to the total number of cycles, it gives $\Delta K=6.4 \cdot 10^{2}$.

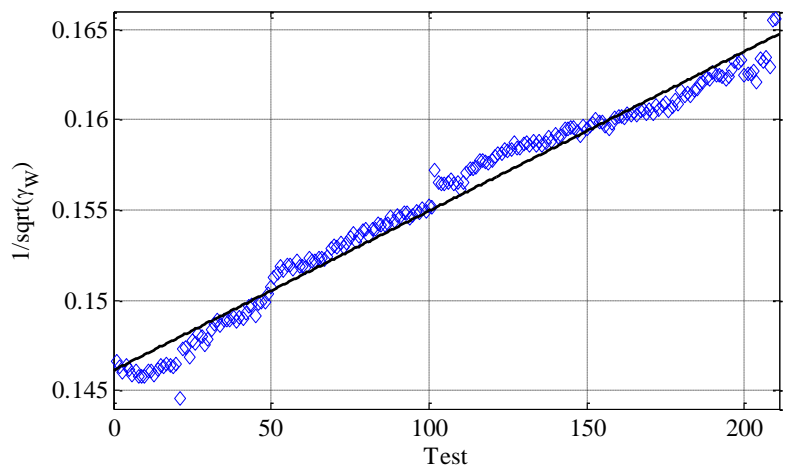

Fig. 12. Fitting of the Paris equation to the evolution of the Wigner-Ville indicator during the final stage of the breakage (c3).

In principle this result links the stress intensity factor to the transient indicators of the bar breakage obtained during a direct startup.

\section{B. Diagnosis module}

Following the system architecture depicted in $[1,6]$, a Particle Filtering approach is implemented as diagnosis module, which permits the combination of both Boolean and continuous variables, the use of non-linear models (7) and an easy linking to prognosis routines, among other advantages.

Given the interest of monitoring a bar breakage and estimating the Remaining Useful Life (RUL) in large machines, this implementation is based on their expected operational conditions, similar to the ones in which the fatigue test was conducted.

A scheme of the implemented module is shown in Fig. 13 (left). The diagnosis routine features the three stages of the Particle Filtering approach [4]. In the first step, prediction, the system transition equations are used to forecast the actual state of the system $x_{t}^{*}$ at cycle $t$ based on the previous known value $x_{t-l}$. The update stage confronts the prediction to the new measurement $\gamma_{W, t}$ when it is available, using the observation equation via the Bayes rule and associating a weight $w$ to each particle $k$. Finally, in the resampling, step the particles are resampled according to their weight and sent back to the prediction stage. The output of the update stage, $\left\{x_{t}(k), w_{t}(k)\right\}$, constitutes a discrete approximation of the probability distribution function of the system's state given the 
measurement, and therefore, statistical quantities can be derived from it.

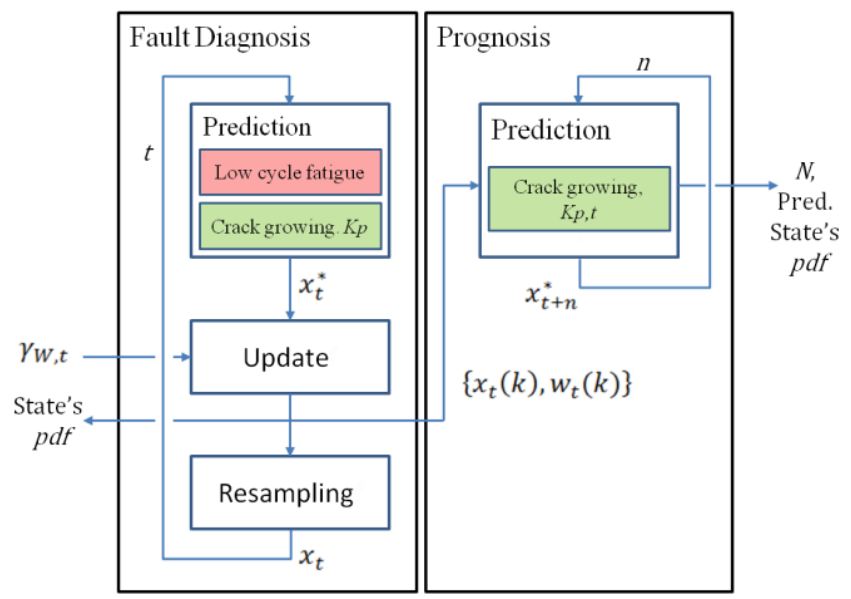

Fig. 13. Diagram showing the proposed Fault Diagnosis and Prognosis module. Given the input of the rotor asymmetry indicator $\gamma_{W}$ at cycle $t$ the Particle Filter-based diagnosis module is able to yield a $p d f$ of the state of the bar. In addition, the particles depicting such estimation can be further propagated using the prediction stage in order to obtain an estimation of the future states at cycle $t+n$.

In this work, the state vector $x_{k}$ is composed by two variables, one discrete signaling the state of the bar and the other continuous evaluating a defect's indicator value (8). For the first one, four states are defined, according to [28]: healthy ("1"), which in this case also includes the compensation stage; hot spots ("2"), breaking ("3") and broken bar ("4"). In the case of the second one, the Wigner-Ville indicator (5) for phase A (Fig. 11) which accurately depicts the evolution of the fault is selected.

$$
x_{t}=\left[\begin{array}{l}
x_{d, t} \\
\gamma_{W, t}
\end{array}\right]
$$

Eq. (9-11) compute the estimated state vector $x_{t}^{*}$. in the prediction stage. Although in this paper $K_{l c}=1$ has been used, Eq. (10) can take into account the natural wear off of the machine during its designed number of startups for $K_{l c}<1$, or can also be replaced by a low-cycle fatigue expression such as the one proposed in [23]. However, if a breaking bar-state is detected, (10) is substituted by the Paris' equation $(7,11)$ in order to estimate the next value of the asymmetry indicator $\gamma_{W, t}^{*}$ :

$$
\begin{gathered}
x_{d, t}^{*}=x_{d, t-1}+n_{d, t-1} \\
\gamma_{W, t}^{*}=K_{l c} \cdot \gamma_{W, t-1}+n_{l c, t-1} \\
\gamma_{W, t}^{*}=\left(\gamma_{W, t-1}^{-1 / 2}+K_{p}\right)^{-2}+n_{p, t-1}
\end{gathered}
$$

where $K_{p}=\frac{1}{6} \cdot C \cdot \Delta K^{3}$, and $n_{t-1}, n_{l c t-1}, n_{p, t-1}$ are zero mean Gaussian noise with standard deviation 0.5, 1 and 0.5.

In the update stage, bibliography thresholds presented in [28] for the FFT indicator used commonly in the industry to assess a bar breakage in large units are used, since the Wigner-

Ville indicator (5) yields similar values (see Table IV). The procedure is complemented by a trend detection code that recognizes long term evolutions in the data that reflect progressing damage. The probability of each particle according to the measurement, which defines its weight, is derived accordingly. The measurement noise for the WignerVille indicators during the final stages of the fatigue test fits a normal distribution, with a standard deviation as presented in Table II.

TABLE IV THRESHOLD VALUES FOR EACH STATE.

\begin{tabular}{ccc}
\hline \hline State & Value & Threshold (dB) \\
\hline $\begin{array}{c}\text { Healthy } \\
\text { ("Compensation") }\end{array}$ & 1 & $\gamma_{\mathrm{W}} \geq 49 \mathrm{~dB}$ \\
\hline Hot Spots & 2 & $44 \mathrm{~dB} \geq \gamma_{\mathrm{W}}>49 \mathrm{~dB}$ \\
\hline Breaking Bar & 3 & $39 \mathrm{~dB} \geq \gamma_{\mathrm{W}}>44 \mathrm{~dB}$ \\
\hline Broken Bar & 4 & $\gamma_{\mathrm{W}}<39 \mathrm{~dB}$ \\
\hline \hline
\end{tabular}

The particles obtained following this procedure constitute a discrete approximation of the probability density function $p d f$ of the state of the bar. Its mean yields the current state whilst the gap between it and the theoretical one's mean allow obtaining a confidence value.

Fig. 14 shows the results of applying the particle filtering approach for the state estimation of the bar during the breakage. In this case, 35 particles have been used $(k=1,2 \ldots 35)$. This procedure detects the damage progression at test number 80,885 , when the asymmetry indicator (blue line in Fig. 14, acquires a downward trend. A broken bar is declared when the resulting state $p d f$ 's mean acquires a value below $39 \mathrm{~dB}$, according to Table IV, which happens at test number 81,040 , that is, 31 cycles before the actual breakage takes place.

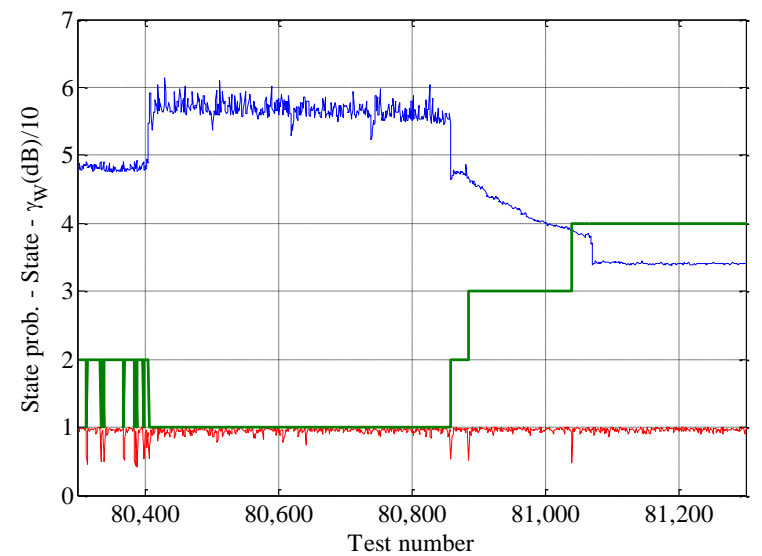

Fig. 14. Results of the state estimation by the particle filtering approach applied to the indicator 5A. Blue line, 5A indicator value divided by 10 ; green line, state (1, healthy ("compensation"); 2 hot spots, 3 breaking bar, 4 broken bar); red line, state probability.

\section{Prognosis module and generalization}

The prognosis module (Fig. 13, right side) has been implemented according to $[1,6]$ as well. Two assumptions are made for its implementation:

1) The machine is operated under constant conditions, as it would correspond to a big unit working in a fixed application.

2) Since the fracture mechanics have not been studied in 
this work, the objective of the prognosis module is not to estimate the remaining operational cycles until the actual breakage occurs, but instead, until the threshold level of $39 \mathrm{~dB}$ is reached. Beyond this point the rupture would be considered imminent.

The prognosis module works, once a breaking bar condition is detected by the diagnosis module, propagating the actual $p d f$ of system's state at time $t$ (approximated by the particles $\left.\left\{x_{t}(k), w_{t}(k)\right\},\right)$ by successively using the Paris' equation (11) in the prediction stage, until the forecasted level for the asymmetry indicator $\gamma_{W, t+n}^{*}$ for cycle $n$ reaches a mean value of $39 \mathrm{~dB}$. The number of cycles needed $N$ represents its RUL computed at $t$. Since there is no update stage, the particle weights remain constant. The result is also a $p d f$ of the future state, which can as well yield statistical quantities in order to reflect the accuracy of the prediction (Fig. 15).

Contrary to the work developed in this paper, in which $K_{p}$, that is, the rate of propagation of the crack used in the Paris' equation $(7,11)$ has been experimentally determined by a fatigue test, in real applications, it would be unknown and linked to design and construction of the cage and the severity of the startup through the stress intensity factor $\Delta K$. Given that Particle Filtering is a combined model and data driven approach and model deviations are corrected by new measurements, an approximation of $K_{p}$ can be used in the diagnosis routine presented in the previous point, however, for prognosis the calculation of its value becomes critical in order to obtain an accurate prediction. Therefore, the first task once a breaking bar is detected would consist of determining $K_{p}$, provided that the long term evolution should fit (7). For this duty, once new particles are available from the update stage at time $t$, a regression is being used to compute a new $K_{p, t}$ coefficient. The prognosis at $t$ is carried out using this new value.

Fig. 15 portrays the smoothed estimation of the bar's RUL once the breaking condition has been detected (test number 80,855 ), for seeded values of $K_{p}$ ranging from $5 \cdot 10^{-5}$ to $9 \cdot 10^{-5}$, compared to the real cycles to failure represented by the black dotted line. The red (upper) and green (lower) dotted lines are established at three times the smoothed standard deviation of the predicted particle values $x_{t+N}^{*}$. As new data becomes available, the accuracy of the prediction increases even for initial values that differ considerably. These results provide an initial generalization of the proposed approach to different severity startups.

Nevertheless, since an induction machine can operate with several broken bars and there exist other kind of defects in the rotor cage, this approach by itself cannot predict the Remaining Useful Life of the machine. This work is focused on a particular failure mode under certain operational conditions. Besides, additional tests with different rotor cage configurations and multiphysics finite element analysis, should be carried out to establish the variation of the stress intensity factor $\Delta K$ in those situations, however, the versatility of the Particle Filtering algorithm proposed here may provide a framework in which new results can be easily integrated.

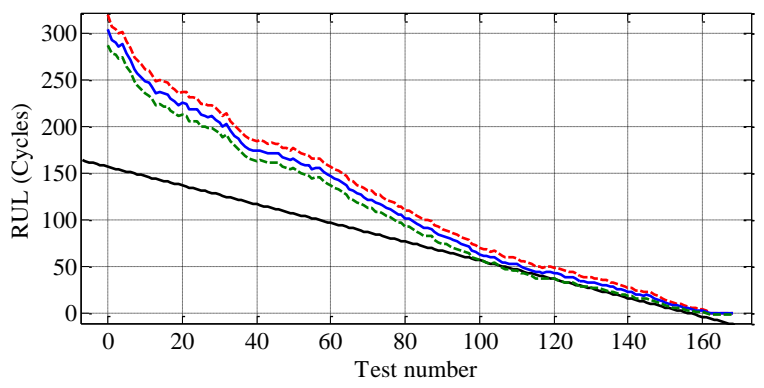

(a)

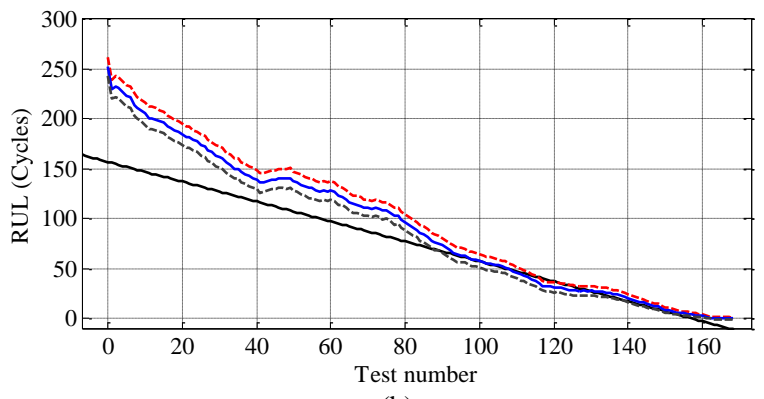

(b)

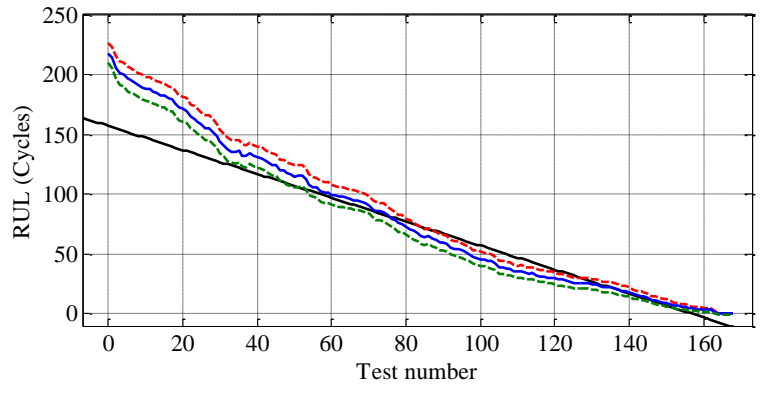

(c)

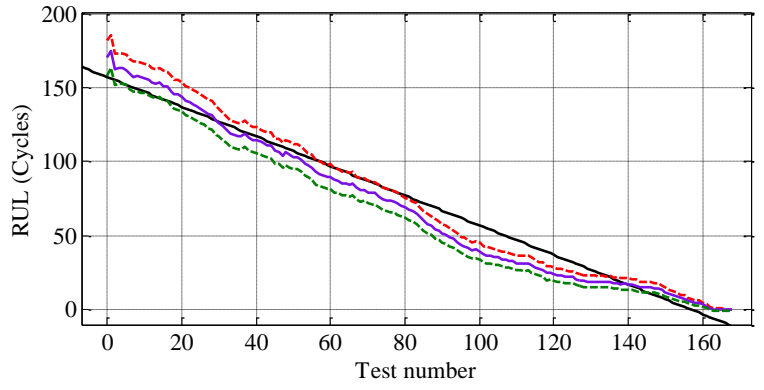

(d)

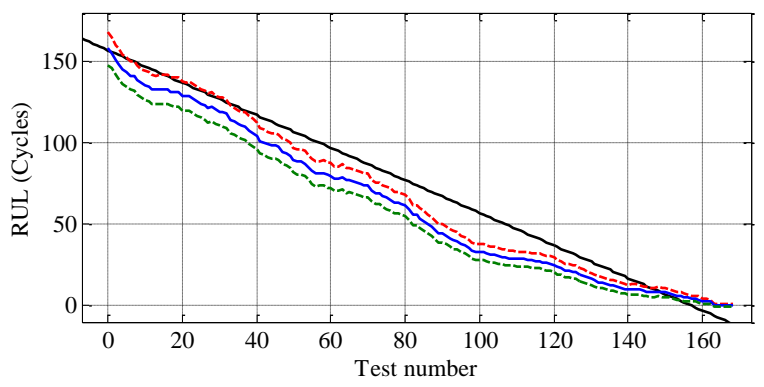

(e)

Fig. 15. Results of the RUL estimation $N$ through the particle filtering approach since the breaking bar condition is detected. Black line, cycles to failure; blue line, estimation for seeded value of $K_{p}=5 \cdot 10^{-5}(\mathrm{a})$, for $6 \cdot 10^{-5}(\mathrm{~b})$, for $7 \cdot 10^{-5}(\mathrm{c})$, for $8 \cdot 10^{-5}(\mathrm{~d})$ and for $9 \cdot 10^{-5}(\mathrm{e})$; red dotted line, upper $3 \sigma$ limit; green dotted, lower $3 \sigma$ limit. 


\section{CONCLUSIONS}

A Condition Based Maintenance and Prognosis and Health Management architecture is presented for determining the state and the remaining useful life (RUL) of a rotor bar in an induction machine, based on the results of a fatigue test designed to produce in the most natural way possible a breakage.

The test has shown that the study of a direct startup's stator current allows tracking the evolution of breaking bar accurately, detecting its failure in an incipient stage, and providing a pattern of its development that permits the fitting of physical failure models with the objective of carrying out the prognosis of the fault.

Those models and the entire Particle Filtering diagnosis and prognosis algorithm provided here, offer a framework to further extend the results to different fault modes and operational conditions, such a multiple bar breakages or end ring failure, with the aim of determining the RUL of the entire machine. Multiphysics Finite Element analysis and fatigue testing would be necessary to establish the stresses on the rotor cage under those configurations.

\section{APPENDIX}

The characteristics of the motor tested are: star connected, rated voltage $\left(\mathrm{U}_{\mathrm{n}}\right): 400 \mathrm{~V}$, rated power $\left(\mathrm{P}_{\mathrm{n}}\right): 1.5 \mathrm{~kW}, 1$ pole pairs, stator rated current $\left(\mathrm{I}_{1 \mathrm{n}}\right): 3.25$ A rated speed $\left(\mathrm{n}_{\mathrm{n}}\right)$ : 2860 rpm.

\section{REFERENCES}

[1] C. Ly, K. Tom, C. S. Byington, R. Patrick, G. J. Vachtsevanos, "Fault diagnosis and failure prognosis for engineering systems: A global perspective Automation Science and Engineering”, 2009. CASE 2009. IEEE International Conference on, 2009 , pp. 108 - 115

[2] O. Ondel, E. Boutleux, E. Blanco, G. Clerc, "Coupling Pattern Recognition With State Estimation Using Kalman Filter for Fault Diagnosis," IEEE Trans. Ind. Electron. Vol. 59, No. 11, 2012

[3] V. Verma, J. Langford, R. Simmon, "Non-Parametric Fault Identification for Space Rovers," International Symposium on Artificial Intelligence and Robotics in Space (iSAIRAS), June, 2001 (http://www.ri.cmu.edu/publication_view.html?pub_id=3759)

[4] A. Doucet, N. de Freitas, N. Gordon, Sequential Monte Carlo Methods in Practice, Springer, 2001

[5] A. Soualhi, H. Razik, G. Clerc, Dinh Dong Doan, "Prognosis of Bearing Failures Using Hidden Markov Models and the Adaptive Neuro-Fuzzy Inference System," IEEE Trans. Ind. Electron., Vol. 61, No. 6, June 2014, pp. $2864-2874$

[6] M. E. Orchard, G. J. Vachtsevanos, "A particle-filtering approach for on-line fault diagnosis and failure prognosis," Transactions of the Institute of Measurement and Control, 2009, 31:221

[7] A. Bellini, F. Filippetti, C. Tassoni, G. -A. Capolino, "Advances in Diagnostic Techniques for Induction Machines," IEEE Trans. Ind. Electron., Vol. 55, No. 12, 2008, pp. 4109-4126

[8] A. Bellini, C. Concari, G. Franchescini, C. Tassoni, A. Toscani, "Vibrations, currents and stray flux signals to asses induction motors rotor conditions." IEEE Industrial Electronics, IECON 2006 - 32nd Annual Conference on, 2006 , pp. $4963-4968$

[9] A. Khezzar, M. Y. Kaikaa, M. El Kamel Oumaamar, M. Boucherma, H. Razik, "On the Use of Slot Harmonics as a Potential Indicator of Rotor Bar Breakage in the Induction Machine," IEEE Trans. Ind. Electron., Vol. 56, No. 11, Nov. 2009, pp. 4592-4605.

[10] J.Faiz, B. M. Ebrahimi, H.A. Toliyat, W.S. Abu-Elhaija, "Mixed-fault diagnosis in induction motors considering varying load and broken bars location," Energy Conversion and Management, Vol. 51, Issue 7, July 2010, pp. 1432-1441
[11] S. Lee, J. Hong, S. B. Lee, E. J. Wiedenbrug, M. Teska, K. Heedong, "Evaluation of the Influence of Rotor Axial Air Ducts on Condition Monitoring of Induction Motors," IEEE Trans. Ind. Appl., Vol. 49, No. 5, 2013, pp. $2024-2033$

[12] S. H. Kia, H. Henao, G.-A. Capolino, "Zoom-MUSIC frequency estimation method for three-phase induction machine fault detection," Industrial Electronics Society, 2005. IECON 2005. 31st Annual Conference of IEEE, 2005, pp. 2603-2608

[13] G. Didier, E. Ternisien, H. Razik, "Detection of incipient rotor cage fault and mechanical abnormalities in induction motor using global modulation index on the line current spectrum," Diagnostics for Electric Machines, Power Electronics and Drives, 2005. SDEMPED 2005. 5th IEEE International Symposium on, 2005 , pp. 1-6

[14] A. O. Di Tommaso, R. Miceli, G. R. Galluzzo, "Monitoring and diagnosis of failures in squirrel-cage induction motors due to cracked or broken bars," Diagnostics for Electric Machines, Power Electronics \& Drives (SDEMPED), 2011 IEEE International Symposium on, 2011, pp. 39-44

[15] F. Vedreño-Santos, M. Riera-Guasp, H. Henao, M. Pineda-Sánchez, R. Puche-Panadero, "Diagnosis of Rotor and Stator Asymmetries in Wound Rotor Induction Machines Under Non- Stationary Operation through the Instantaneous Frequency," IEEE Trans. Ind. Electron., (DOI: 10.1109/TIE.2013.2288192).

[16] S. Elder, J. F. Watson, W. T. Thomson, "Fault detection in induction motors as a result of transient analysis," Electrical Machines and Drives, 1989. Fourth International Conference on, pp. 182 - 186, 1989

[17] M. F. Cabanas, J. L. Ruiz Gonzalez, J. L. B. Sampayo, M. G. Melero, C. H. Rojas, F. Pedrayes, A. Arguelles, J. Vina, "Analysis of the fatigue causes on the rotor bars of squirrel cage asynchronous motors: experimental analysis and modelling of medium voltage motors," Diagnostics for Electric Machines, Power Electronics and Drives, 2003. SDEMPED 2003. 4th IEEE International Symposium on, 2003 , pp. 247 $-252$

[18] C. D. Pitis, "Thermo-Mechanical Stresses of the Squirrel Cage Rotors in Adverse Load Conditions," Electrical Insulation, 2008. ISEI 2008. Conference Record of the 2008 IEEE International Symposium on, 2008, pp. 579-585

[19] R. Yabiku, R. Fialho, L. Teran, M. E. Ramos, N. Kawasaki, "Use of Thermal Network on Determining the Temperature Distribution Inside Electric Motors in Steady-State and Dynamic Conditions," Industry Applications, IEEE Transactions on, Vol. 46, No. 5, 2010, pp. 17871795

[20] M. Hodowanec, W. R. Finley, Copper Versus Aluminum-Which Construction Is Best? [Induction Motor Rotors], Industry Applications Magazine, IEEE, Vol. 8, pp. 14-25, 2002

[21] G. R. Halford, Low-Cycle Thermal Fatigue, NASA Technical Memorandum 87225, Lewis Research Center, Cleveland, OH., 1986.

[22] V. Climente-Alarcon, M. Riera-Guasp, J. A. Antonino-Daviu, J. Roger Folch, "Experimental study of the evolution of a bar breakage process in a commercial induction machine", Electrical Machines, 2008. ICEM 2008. 18th International Conference on, pp. 1 - 5, 2008

[23] V. Climente-Alarcon, J. A. Antonino-Daviu, E. Strangas, M. RieraGuasp, "Bar Breakage Mechanism and Prognosis in an Induction Motor," in Proc. of IEEE International Symposium on Diagnostics for Electric Machines, Power Electronics and Drives, SDEMPED, Valencia, Spain, 2013, pp. 538-545.

[24] V. Kandia, Y. Stylianou, "Detection of Creak Clicks of Sperm Whales in low SNR conditions" IEEE Oceans - Europe 2005 pp. 1052-1057

[25] V. Climente-Alarcon, J. Antonino-Daviu, M. Riera-Guasp, M. Vlcek, "Induction Motor Diagnosis by Advanced Notch FIR Filters and the Wigner-Ville Distribution," IEEE Trans. Ind. Electron., Vol. 61, Aug. 2014, pp. 4217-4227

[26] M. Riera-Guasp, M. F. Cabanas, J. A. Antonino-Daviu, M. PinedaSanchez, C. H. R. Garcia, "Influence of Nonconsecutive Bar Breakages in Motor Current Signature Analysis for the Diagnosis of Rotor Faults in Induction Motors", IEEE Trans. Energy Conv., Vol. 25, 2010, pp. 8089.

[27] "Evolution of High Order Fault Harmonics during a Bar Breakage with Compensation," Electrical Machines, 2014. ICEM 2014. 21st International Conference on, Berlin, Germany, 2014 (accepted for presentation)

[28] M. Fernández Cabanas, M. García Melero, G. Alonso Orcajo, J.M. Cano Rodríguez, J. Solares Sariego, in: Marcombo-Boixareu (Ed.), Maintenance and Diagnosis Techniques for Rotating Electric Machinery, ABB, Service, S.A., Barcelona, 1999. 


\section{BIOGRAPHIES}

Vicente Climente-Alarcon (S'11-M'12) received his M.Sc. degrees in Chemical and Industrial Engineering in 2000 and 2011, and his Ph.D. degree in Electrical Engineering in 2012, all from the Universitat Politècnica de València (Spain).

He has worked as Assistant Professor in the School of Industrial Engineering of the mentioned university, on research tasks in the area of condition monitoring of electrical machines, and externally as a consultant in automation and management of power systems. Currently he is carrying out postdoctoral research at the Department of Electrical Engineering and Automation, Aalto University, Espoo, Finland.

Jose Antonino-Daviu (M'08-SM'12) received his M.S. and Ph. D. degrees in Electrical Engineering, both from the Universitat Politècnica de València, in 2000 and 2006, respectively. He was working for IBM during 2 years, being involved in several international projects. Currently, he is Associate Professor in the Department of Electrical Engineering of the mentioned University, where he develops his docent and research work. He has been invited professor in Helsinki University of Technology (Finland) in 2005 and 2007 and in Michigan State University (USA) in 2010. He has over 60 publications between international journals, conferences and books. His primary research interests are condition monitoring of electric machines, wavelet theory and its application to fault diagnosis and design and optimization of electrical installations and systems.

Elias G. Strangas ( $\left.\mathrm{S}^{\prime} 74-\mathrm{M}^{\prime} 80\right)$ received the Dipl. Eng. degree in electrical engineering from the National Technical University, Athens, Greece, in 1976, and the Ph.D. from the University of Pittsburgh, Pittsburgh, PA, in 1980.

$\mathrm{He}$ has worked in industry (Schneider Electric) and at the University of Missouri-Rolla from 1983 to 1985. Since 1986, he has been with Michigan State University, where he directs the Electrical Machines and Drives Laboratory. His technical interests are in the design and control of electrical machines and drives and has published extensively in these fields. For the last ten years, he and his students have been working on the fault diagnosis and failure prognosis of electrical machines, using model and data based methods. Their work has been funded by industry and the State and Federal governments.

Martín Riera-Guasp (M'04-SM'12) received the M. Sc. degree in industrial engineering and the Ph.D. degree in electrical engineering from the Universitat Politècnica de València, Valencia (Spain), in 1981 and 1987, respectively.

Currently, he is an Associate Professor with the Department of Electrical Engineering, Polytechnic University of Valencia. His research interests include condition monitoring of electrical machines, applications of the Wavelet Theory to electrical engineering and efficiency in electric power applications. 